\title{
A CROSS SECTIONAL STUDY OF FACTORS AFFECTING SEVERITY OF MENTAL RETARDATION
}

\author{
Usha Venkata Ramana Lanka1, Srilakshmi P2
}

${ }^{1}$ Associate Professor, Department of Psychiatry, Institute of Mental Health, Osmania Medical College. ${ }^{2}$ Assistant Professor, Department of Psychiatry, Institute of Mental Health, Osmania Medical College.

ABSTRACT: BACKGROUND: Mental retardation (MR) is seen in 2 to 3 percent of the population, either as an isolated finding or as part of a syndrome or broader disorder. Various factors have been found to be associated with severity of mental retardation. Sociodemographic factors, genetic factors, perinatal factors and associated co morbid conditions influence the severity of MR. These factors need to be understood from prevention point of view.

MATERIALS AND METHODS: Children between the ages of 6-18 years were selected by purposive sampling in a cross sectional study. The sample size was 108. Data was collected by a semi structured intake proforma including socio-demographic data, presenting complaints and perinatal factors. Physical, psychological examination and assessment for Co morbidities was done. Intelligence Quotient was assessed. Data was statistically analysed.

RESULTS AND OBSERVATION: Majority of the children were males, the mean age was 11.38 and standard deviation 5.76, the families were more from lower socio economic class, with mother's age ranging between 15-20 years, and father's between 20-30 years. Parents were mostly illiterate and unskilled labourers. Three presenting complaints of convulsions, no toilet training and delayed walking were found to be significantly associated with the diagnosis. History of septicaemia and meningitis/encephalitis were the perinatal factors significantly associated with the severity of mental retardation. Seizures as a co morbid condition was significantly associated with mental retardation.

CONCLUSION: A knowledge of the factors associated with severity of mental retardation helps to initiate early intervention and take preventive measures.

KEYWORDS: Mental Retardation, Severity, Factors.

HOW TO CITE THIS ARTICLE: Usha Venkata Ramana Lanka, Srilakshmi P. “A Cross Sectional Study of Factors Affecting Severity of Mental Retardation”. Journal of Evolution of Medical and Dental Sciences 2015; Vol. 4, Issue 89, November 05; Page: 15426-15432, DOI: $10.14260 /$ jemds/2015/2201.

INTRODUCTION: Mental retardation(MR) is defined as a "Significantly sub average intellectual functioning existing concurrently with related limitations in two or more of the following applicable adaptive skill areas: communication, selfcare, home living, social skills, community use, selfdirection, health and safety, functional academics, leisure and work, with such limitations manifested before the age of 18. ${ }^{1}$ Mental retardation is seen in 2 to 3 percent of the population, either as an isolated finding or as part of a syndrome or broader disorder. ${ }^{2}$ The prevalence in India varies from $0.22 \%-3.7 \% .^{3}$ Mental retardation is further classified into four subtypes on the basis of intelligence quotient (IQ); mild (IQ=50-70); moderate (IQ=35-49); severe-(IQ=20-34) and Profound $(\mathrm{IQ}=<20)$.

Corresponding mental ages in each group is $9-12$ years; 6-9years 3-6 years and less than 3 years respectively. ${ }^{4}$ Amongst the subtypes of mental retardation, mild mental retardation is the most common, affecting about 85\%; moderate mental retardation $10 \%$; severe mental retardation about $3-4 \%$ and profound mental retardation about $1-2 \% .5$ The commonest aetiology was Down's Syndrome accounting for about $5-20 \%$ of all cases;

Financial or Other, Competing Interest: None.

Submission 14-10-2015, Peer Review 15-10-2015,

Acceptance 24-10-2015, Published 04-11-2015.

Corresponding Author:

Dr. Usha Venkata Ramana Lanka,

Address: 8-9-169/A/45/D-1, Surya Residency, Siddhartha Nagar,

Vengalrao Nagar, Hyderabad-500038, Telangana.

E-mail: dasikausha@gmail.com

DOI:10.14260/jemds/2015/2201. congenital hypothyroidism in 1-2\% of cases; other common causes noted were low birth weight and prematurity, birth injuries and birth asphyxia, and childhood infections affecting the neurological system and about $30-50 \%$ cases were of unknown etiology. ${ }^{6}$ Various factors have been studied as possible factors affecting the severity of mental retardation.

Studies support low socioeconomic status association with mild mental retardation.7,8 Besides sociodemographic factors, genetic factors, perinatal factors and associated co morbid conditions also influence the severity of MR. Delay in diagnosis leads to delay in starting intervention programs for the child thus affecting the prognosis. The delay in seeking help was influenced by the symptomatology, education and awareness of caregivers, severity of MR and the associated co morbid conditions. As there are few Indian studies in this field; this study was undertaken to understand such factors from the Indian perspective.

AIMS AND OBJECTIVES: To study the factors affecting severity of mental retardation in a tertiary child guidance referral centre.

MATERIALS AND METHODS: This study was conducted in an urban government tertiary referral centre for Child Psychiatry and Child guidance clinic. Appropriate permission was obtained from the institute for the study.

Study Universe: Children between the ages of 6-18 years, who fulfilled the inclusion criteria were selected for study.

Study Design: Cross-sectional study.

Sampling Design: Purposive sampling. 
Sample size: The sample size was 108.

Data Collection: All children between the age group 6-18 years were taken up for study. Prior permission was obtained from the institute for the study. Informed consent was obtained from the parents/caretakers as the children were minors. Inclusion criteria included children aged between 6-18 years, parents/guardians consenting for the study, children with IQ below 70. Exclusion criteria was age $<6$ years and $>18$ years, those not consenting for the study for various reasons and children with IQ above 70 .

Sociodemographic data was obtained from each child and their guardians and entered in a semi structured proforma. Major presenting complaints of each child as expressed by the parent/guardian were noted. Antenatal, natal and postnatal details were obtained from each. Detailed physical and psychological examination was done for each child to assess the co morbidities.

Intelligence Quotient: Intelligence Quotient (IQ) was assessed by clinical psychologist using Binet Kamat test. ${ }^{9}$ The Binet Kamat test of intelligence is one of the widely used intelligence tests in Indian clinical setup. This scale is an Indian adaptation of the Stanford-Binet scale of intelligence, prepared in 1934 and standardized by V. V. Kamat in 1964 and re-evaluated in 1967. The reliability of the Binet-Kamat test is reportedly above 0.7 and the validity of this test for normal children against estimation of intelligence quotient by teachers is 0.5 .

Statistics: The data collected was compiled and analyzed statistically. Mean, Standard deviation was calculated wherever relevant. Chi square test was done to compare the variables. The level of significance was set at $p \leq 0.05$.

RESULTS: Table no. 1 depicts comparison of presenting complaints across the subtypes of MR. Presenting complaints by caretakers was less intellect in $53.7 \%$; speech delay in 41.7\%; scholastic backwardness in $10.2 \%$; behavioural problems in $19.4 \%$; delayed walking in $15.7 \%$; seizures in $7.4 \%$; poor vision in $2.8 \%$; hearing impaired in $0.9 \%$; no self-care in $1.9 \%$; not toilet trained in $1.9 \%$ and self-injurious behaviour in $0.9 \% .63 .9 \%$ caretakers came for issue of disability certificate.

Three complaints reached statistical significance, delayed walking, not toilet trained and seizures. Delayed walking as presenting complaint was statistically significant across diagnosis. $41.2 \%$ of children with delayed walking had moderate MR; $29.4 \%$ had severe MR; $17.6 \%$ had mild MR and $11.8 \%$ had profound MR.

Not toilet trained was also statistically significant when compared with diagnosis. One child each with moderate and profound MR was brought for no toilet training. Seizures as presenting complaints was also statistically significant when compared across diagnosis. Children with convulsions were equally distributed in the 4 subtypes of MR. $40 \%$ of cases with no history of convulsions had Mild MR; 32\% had Moderate MR, $27 \%$ had severe MR and 1\% had Profound MR.

Table No. 2A and 2B depicts the comparison between socio demographic factors and the subtypes of MR. the age range of children was statistically significant when compared across diagnosis.

$40.7 \%$ patients were in the age range $6-8$ years; $38 \%$ were in the age range $9-11$ years; $21.3 \%$ were in the age range $12-14$ years. There is a significant difference when age range of patient was compared with subtype of mental retardation. In the age range 6-8 years; $52.3 \%$ patients had mild MR, 31.8\% had moderate MR; $13.6 \%$ had severe MR and $2.3 \%$ had profound MR. In the age range $9-11$ years; $34.1 \%$ had mild and moderate MR each, $26.8 \%$ had severe MR and $4.9 \%$ had profound MR. In the age range $12-14$ years; $27.1 \%$ had mild, $26.1 \%$ had moderate, $52.2 \%$ had severe and none had profound MR.

Socio economic status was significantly associated when compared with diagnosis. Upper socioeconomic status represented $26 \%$ and lower $74 \%$. In the upper Socio economic status $60.7 \%$ had mild MR whereas $17.9 \%$ each had moderate and severe MR and 3.6\% had profound MR. 31.3\% cases from low socioeconomic status had mild MR, $36.3 \%$ had moderate; $30 \%$ had severe and $2.5 \%$ had profound MR. There is significant difference between the groups when socioeconomic status was compared with MR severity.

There was over representation of males (62\%), majority $(81.5 \%)$ were either $1^{\text {st }}$ or $2^{\text {nd }}$ birth order, Hindus and Muslims were almost equally represented (49\% Muslims, 39\% Hindus), majority came from urban background (56\%) and Nuclear families $(69 \%)$ and were products of non-consanguineous marriage (64\%).

Mother's age ranged from 15-20 years (61\%) whereas fathers age ranged from 21-30 years (61\%). Mean age of father at conception was 26.69 years with standard deviation 5.85 . Mean age of mother at conception was 20.94 years and standard deviation was 5.02 .

Majority of both fathers (54\%) and mothers (69.4\%) were illiterate.58.3\% of mothers were unskilled labourers; $54 \%$ of fathers were unskilled labourers. $50 \%$ of families had monthly income Rs1600-8000, 10.2\% had 1 sibling affected and 7.4\% had 2 siblings affected.

There is no difference as far as gender is concerned when compared with MR subtypes. $43.9 \%$ of females had mild MR, $29.3 \%$ had moderate, $26.8 \%$ had severe and none had profound MR whereas $35.8 \%$ of males had mild MR, $32.8 \%$ had moderate, $26.9 \%$ had severe and $4.5 \%$ had profound MR. 63 children were in the age range of 9-14 years and 45 children were between 6-8 years. The mean age was 11.38 and standard deviation 5.76 .

Table 3: Depicts the relationship of perinatal factors with the severity of MR $44.8 \%$ of patients with caesarean delivery had mild MR as against $36.7 \%$ with normal delivery. $27.6 \%$ of patients with caesarean delivery had moderate MR against $32.9 \%$ with normal delivery. $24.1 \%$ patients with caesarean delivery had severe MR against $27.8 \%$ with normal delivery and $3.4 \%$ patients with caesarean deliveries had profound MR against $2.5 \%$ with normal delivery.

There was no difference when the groups were compared with type of delivery. $41.2 \%$ with preterm delivery had mild MR against $38.5 \%$ with term delivery. $35.3 \%$ with preterm delivery had moderate MR against $30.8 \%$ with term delivery. $23.5 \%$ with preterm delivery had severe MR against $27.5 \%$ with term delivery. 
All the profound MR cases were products of term delivery and constituted $3.3 \%$ of all term deliveries. There was however no statistically significant difference between the groups when compared.

$35.9 \%$ patients with birth asphyxia had mild MR, 33.3\%, moderate MR, 30.8\%, severe and none had profound MR. $40.6 \%$ without birth asphyxia had mild MR, 30.4\% had moderate, $24.6 \%$ had severe and $4.3 \%$ had profound. There was no statistically significant difference when the sub groups were compared. Severity of MR could not be statistically associated with birth asphyxia suggesting role of some other factors. Presence of septicaemia was however statistically significantly associated with severity of MR. $33.3 \%$ of patients with septicaemia had mild MR, severe and profound MR each.

There were no patients with moderate MR with history of septicaemia. This could be due to small sample size or other factors which need to be evaluated. 39\% children without septicaemia had mild, 32.4.\% had moderate, $26.7 \%$ had severe and $1.9 \%$ had profound MR. History of meningitis/encephalitis was also significantly associated with severity of MR. $28.6 \%$ of patients with history of meningitis/encephalitis had mild MR, 71.4\% had severe MR whereas none had moderate/profound MR. This observation needs to be further studied with a larger sample and other influencing factors also need to be evaluated. Amongst children without history of meningitis/encephalitis 39.6\% had mild MR, $33.7 \%$ had moderate $23.8 \%$ had severe and $3 \%$ had profound MR.

The co morbidities detected in the present study (Table 4) were seizures, Down's syndrome, hypothyroidism, autism, squint, hearing impairment, visual impairment, congenital heart disease (CHD), microcephaly, cardiovascular accidents (CVA) and behavioural problems. Seizures were the only statistically significant co morbidity. $37.5 \%$ of patients with history of seizure had Severe MR; 25\% each had Mild and Moderate MR and only 12.5\% patients had Profound MR. 42.9\% patients with absent seizure history had Mild MR, 33.3\% had moderate, 23.8\% had severe and none had profound MR. Whether this is a chance finding because of small sample or there are other factors also playing a role has to be further evaluated.

DISCUSSION \& CONCLUSIONS: The association of low socio economic class with mental retardation which was found in our study has also been documented by other studies. ${ }^{7,8}$ The reasons hypothesized to account for this association have been perinatal infections and lack of screening for congenital/chromosomal anomalies.7,8 Almost all studies report the prevalence of mental retardation to be higher among males than females, especially among children less than 15 years of age, 10 as was determined by our study. This is especially true for mild mental retardation where males have about a 1.5 -fold greater prevalence.

A number of reasons are suggested for greater prevalence in male children.11,12 Frequent identification among boys maybe due to abnormal behavioural patterns in school, increased adverse effects of maternal smoking and low birth-weight on the neurological development among males. ${ }^{11,12}$
Gender differences were not evident among adults. ${ }^{11,12}$ Researchers have found a correlation between low maternal education and prevalence of intellectual disability. ${ }^{11}$ Some studies have found paternal literacy up to high school and above to be associated with mental retardation which probably reflected the role of education, lesser social stigma and early identification of disability. ${ }^{7}$ Some studies have found that age more than 40 years in father was associated with mild to moderate mental retardation. ${ }^{13}$

In our study the perinatal factors that were significantly associated with severity of MR included septicaemia and history of meningitis and encephalitis which was also noted in earlier studies. ${ }^{6}$ Other factors were not significant. But other studies have shown mild-moderate MR being associated with antenatal factors like pregnancy induced hypertension, asthma, urinary tract infection and some types of ante-partum haemorrhage. ${ }^{14}$ Natal factors associated were preterm birth, elective caesarean sections, breech presentation, poor foetal growth and need for resuscitation at birth. ${ }^{14}$ Severe MR was positively associated with poor foetal growth and need for resuscitation and delivery complications. ${ }^{14}$

A study from Bangladesh has shown the factors associated with severe MR to be maternal goitre, postnatal brain infections, consanguinity and landlessness reflecting lower socioeconomic status. ${ }^{15}$ Whereas factors associated with mild mental retardation were maternal illiteracy, landlessness, maternal history of pregnancy loss and small for gestational age at birth. 15

Studies have shown around $10 \%$ of children with mental retardation have a hearing impairment; seizure disorder is present in a third of institutionalized children with mental retardation and $3-18 \%$ of those with mild-moderate intellectual disability; Cerebral palsy is present in $30-60 \%$ of those with severe to profound intellectual disability. ${ }^{16}$ Studies in adults with intellectual disability showed that they had twice the rate of physical health problems than normal adults in the community. ${ }^{17}$

Autism and other developmental disorders, attention deficit and hyperactivity disorder (ADHD), behavioural disorders, and cerebral palsy are common in children with MR.18 Different studies in the review showed that among children with mental retardation, autism is present in about $25 \%$, ADHD in about $10 \%$, and cerebral palsy in $7-30 \%$, depending on the severity of mental retardation. ${ }^{18}$

The prevalence of conduct disorder, anxiety disorder, ADHD and autism was significantly greater among children with MR than compared to their non-MR peers. ${ }^{18}$ Factors associated with an increased risk of psychopathology among children and adolescents with MR include age, gender, social deprivation, family composition, number of potentially stressful life events, the mental health of the child's primary caregivers, family functioning and child management practices. ${ }^{19}$

Our study has also documented the above co morbidities, of which seizures have a significant association. There were 5 children with down's syndrome in our study of which 2(40\%) each had mild and severe MR and $1(20 \%)$ child had moderate MR. Among adults with Down's syndrome, dementia is the most common cause of mortality and morbidity and research from the Netherlands has found that often it has an 
earlier age of onset (8.9\% in 45-49 year old age-group) compared to the general population. ${ }^{20}$ Down's syndrome with its associated morbidity and mortality has to be ruled out in all children with mental retardation.

Some factors, found significant in other studies, have not been replicated in our study. This finding has to be interpreted with caution as ours was a small sample from a tertiary referral centre and not from the general population.

As there is no cure for mental retardation and causes significant caregiver burden on parents and the State, the focus of intervention should predominantly be on primary prevention. Low socioeconomic status and illiteracy are factors that can be corrected by State level measures thereby reducing the burden of mental retardation.

LIMITATIONS AND FUTURE RECOMMENDATIONS: This was a cross sectional study with a relatively small sample of patients. Study was limited to urban government tertiary referral centre and the associated referral bias. A larger population based sample and a longitudinal study including interventions and their efficacy in preventing will be more conclusive.

\section{REFERENCES:}

1. American Psychiatric Association. (2000). Diagnostic and statistical manual of mental disorders (4th ed., text rev.). Washington, DC.

2. Curry CJ, Stevenson RE, Aughton D, Byrne J, Carey JC, Cassidy S, et al. Evaluation of mental retardation: Recommendations of a consensus conference. Am J Med Genet. 1997; 72:468-77.

3. Thiyam K S, Vishal I, Ramasubba Reddy I. Impact of Disability of Mentally Retarded Persons on their Parents. Indian J Psychol Med; Jul- Dec 2008; 30(2):98-104.

4. Volkmar FR, Dykens E. Mental retardation. In: Rutter M, Taylor E, editors. Child and Adolescent psychiatry. 4th ed.2002.

5. King BH, Toth KE, Hodapp RM, Dykens EM. 2009. Intellectual Disability. In: BJ Sadock, VA Sadock, P Ruiz, editors. Comprehensive Textbook of Psychiatry. 9th ed. Philadelphia: Lippincott Williams \& Wilkins. P. 3444-74.

6. Maulik PK, Harbour CK. 2010. Epidemiology of Intellectual Disability. In: JH Stone, M Blouin, editors. International Encyclopedia of Rehabilitation.

7. Shailja S, Sunil K R, Ashok K B, et al. Socio demography of mental retardation: A Community based study from a goitre zone in rural sub Himalayan India. Journal of Neurosciences in Rural Practice 2015; 6 (2):165.
8. Stromme P, Valvatne K. Mental retardation in Norway: prevalence and sub-classification in a cohort of 30037 children born between 1980 and 1985. Acta Paediatr 1998; 87: 291-96.

9. Kamat VV.1967.Measuring Intelligence of Indian Children. $4^{\text {th }}$ edition. Oxford University Press.

10. Bhagya B. \& Ramakrishna A. Prevalence of mental retardation among children in Mangalore. Nitte University Journal of Health Science 2013; 3(4):63-66.

11. Leonard $H$, Wen $X$. The epidemiology of mental retardation: challenges and opportunities in the new millennium. Mental Retardation and Developmental Disabilities Research Review 2002; 8(3) 117-34.

12. Gissler M, Jarvelin MR, Louhiala P, Hemminki E. 1999. Boys have more health problems in childhood than girls: followup of the 1987 Finnish birth cohort. Acta Paediatrica 88:310-14.

13. Leonard H, Glasson E, Nassar N, Whitehouse A et al. Autism and intellectual disability are differentially related to sociodemographic background at birth. Plos One. 2011 Mar 30; 6(3):e17875. Doi: 10.1371/journal.pone.0017875.

14. Amanda TL, Emma JG, Natasha $\mathrm{N}$ et al. Maternal conditions and perinatal characteristics associated with Autism Spectrum Disorder and Intellectual Disability. Plos One. 2013; 8(1): e50963.Published online 2013 Jan 7.

15. Durkin MS , Khan NZ, Davidson LL ,Huq S, Munir S et al. Prenatal and Postnatal Risk Factors for Mental Retardation among Children in Bangladesh. Am .J. Epidemiol 2000; 152 (11):1024-33.

16. Khess CR, Dutta I, Chakrabarty I, Bhattacharya P, Das J, Kothari S. Co morbidity in children with mental retardation. Indian J Psychiatry 1998 Jul; 40(3):289-94.

17. Hermans H, Evenhuis HM. Multimorbidity in older adults with intellectual disabilities. Res Dev Disabil 2014; 35(4):776-83.

18. Shea SE. Mental retardation in children ages 6 to 16 . Semin Pediatric Neurology 2006; 13:262-70.

19. Emerson E. Prevalence of psychiatric disorders in children and adolescents with and without intellectual disability. J Intellect Disabil Res. 2003; 47(1):51-8.

20. Coppus A, Evenhuis H, Verberne GJ, Visser F, van Gool P, Eikelenboom P, et al. Dementia and mortality in persons with Down's syndrome. Journal of Intellectual Disability Research. 2006; 50:768-7.

\begin{tabular}{|c|c|c|c|c|c|}
\hline Complaint & Mild & Moderate & Severe & Profound & Chi-sq;df \\
\hline \multicolumn{6}{|c|}{ Less intellect } \\
\hline Absent & $23(46 \%)$ & $14(28 \%)$ & $11(22 \%)$ & $2(4 \%)$ & \multirow{2}{*}{$0.41(3)$} \\
\hline Present & $19(32.8 \%)$ & $20(34.5 \%)$ & $18(31 \%)$ & $1(1.7 \%)$ & \\
\hline \multicolumn{6}{|c|}{ Delayed walking } \\
\hline Absent & $39(42.9 \%)$ & $27(29.7 \%)$ & $24(26.4 \%)$ & $1(1.1 \%)$ & \multirow{2}{*}{$0.03(3)^{*}$} \\
\hline Present & $3(17.6 \%)$ & $7(41.2 \%)$ & $5(29.4 \%)$ & $2(11.8 \%)$ & \\
\hline \multicolumn{6}{|c|}{ Delayed speech } \\
\hline Absent & $26(41.3 \%)$ & $20(31.7 \%)$ & $16(25.4 \%)$ & $1(1.6 \%)$ & \multirow{2}{*}{$0.77(3)$} \\
\hline Present & $16(35.6 \%)$ & $14(31.1 \%)$ & $13(28.9 \%)$ & $2(4.4 \%)$ & \\
\hline \multicolumn{6}{|c|}{ Not toilet trained } \\
\hline Absent & $42(39.6 \%)$ & $33(31.1 \%)$ & $29(27.4 \%)$ & $2(1.9 \%)$ & \multirow{2}{*}{$0.00(3)^{*}$} \\
\hline Present & $0(0 \%)$ & $1(50 \%)$ & $0(0 \%)$ & $1(50 \%)$ & \\
\hline
\end{tabular}




\begin{tabular}{|c|c|c|c|c|c|}
\hline \multicolumn{6}{|c|}{ Poor vision } \\
\hline Absent & $39(37.1 \%)$ & $34(32.4 \%)$ & $29(27.6 \%)$ & $3(2.9 \%)$ & \multirow{2}{*}{$0.18(3)$} \\
\hline Present & $3(100 \%)$ & $0(0 \%)$ & $0(0 \%)$ & $0(0 \%)$ & \\
\hline \multicolumn{6}{|c|}{ No self-care } \\
\hline Absent & $42(39.6 \%)$ & $34(32.1 \%)$ & $27(25.5 \%)$ & $3(2.8 \%)$ & \multirow{2}{*}{$0.14(3)$} \\
\hline Present & $0(0 \%)$ & $0(0 \%)$ & $2(100 \%)$ & $0(0 \%)$ & \\
\hline \multicolumn{6}{|c|}{ Hearing impaired } \\
\hline Absent & $41(38.3 \%)$ & $34(31.8 \%)$ & $29(27.1 \%)$ & $3(2.8 \%)$ & \multirow[b]{2}{*}{$0.66(3)$} \\
\hline Present & $1(100 \%)$ & $0(0 \%)$ & $0(0 \%)$ & $0(0 \%)$ & \\
\hline \multicolumn{6}{|c|}{ Convulsions } \\
\hline Absent & $40(40 \%)$ & $32(32 \%)$ & $27(27 \%)$ & $1(1 \%)$ & \multirow{2}{*}{$0.00(3)^{*}$} \\
\hline Present & $2(25 \%)$ & $2(25 \%)$ & $2(25 \%)$ & $2(25 \%)$ & \\
\hline \multicolumn{6}{|c|}{ Self-injurious behaviour } \\
\hline Absent & $42(39.3 \%)$ & $34(31.8 \%)$ & $28(26.2 \%)$ & $3(2.8 \%)$ & \multirow{2}{*}{$0.43(3)$} \\
\hline Present & $0(0 \%)$ & $0(0 \%)$ & $1(100 \%)$ & $0(0 \%)$ & \\
\hline \multicolumn{6}{|c|}{ Scholastic backwardness } \\
\hline Absent & $34(35.1 \%)$ & $31(32 \%)$ & $29(29.9 \%)$ & $3(3.1 \%)$ & \multirow[b]{2}{*}{$0.06(3)$} \\
\hline Present & $8(72.7 \%)$ & $3(27.3 \%)$ & $0(0 \%)$ & $0(0 \%)$ & \\
\hline \multicolumn{6}{|c|}{ Behavioural problems } \\
\hline Absent & $32(36.8 \%)$ & $28(32.2 \%)$ & $24(27.6 \%)$ & $3(3.4 \%)$ & \multirow{2}{*}{$0.71(3)$} \\
\hline Present & $10(47.6 \%)$ & $6(28.6 \%)$ & $5(23.8 \%)$ & $0(0 \%)$ & \\
\hline \multicolumn{6}{|c|}{ Certificate } \\
\hline No & $17(43.6 \%)$ & $11(28.2 \%)$ & $10(25.6 \%)$ & $1(2.6 \%)$ & \multirow[b]{2}{*}{$0.9(3)$} \\
\hline Yes & $25(36.2 \%)$ & $23(33.3 \%)$ & $19(27.5 \%)$ & $2(2.9 \%)$ & \\
\hline
\end{tabular}

* Statistically Significant

\begin{tabular}{|c|c|c|c|c|c|}
\hline Parameter & Mild & Moderate & Severe & Profound & Chi-sq;df \\
\hline \multicolumn{6}{|c|}{ Age of child } \\
\hline 6-8 years & $23(52.3 \%)$ & $14(31.8 \%)$ & $6(13.6 \%)$ & $1(2.3 \%)$ & \multirow{3}{*}{$0.03(6)^{*}$} \\
\hline 9-11 years & $14(34.1 \%)$ & $14(34.1 \%)$ & $11(26.8 \%)$ & $2(4.9 \%)$ & \\
\hline $12-14$ years & $5(21.7 \%)$ & $6(26.1 \%)$ & $12(52.2 \%)$ & $0(0 \%)$ & \\
\hline \multicolumn{6}{|c|}{ Gender } \\
\hline Female & $18(43.9 \%)$ & $12(29.3 \%)$ & $11(26.8 \%)$ & $0(0 \%)$ & \multirow{2}{*}{$0.5(3)$} \\
\hline Male & $24(35.8 \%)$ & $22(32.8 \%)$ & $18(26.9 \%)$ & $3(4.5 \%)$ & \\
\hline \multicolumn{6}{|c|}{ Birth Order } \\
\hline 1 & $20(39.2 \%)$ & $15(29.4 \%)$ & $13(25.5 \%)$ & $3(5.9 \%)$ & \multirow{5}{*}{$0.49(12)$} \\
\hline 2 & $18(48.6 \%)$ & $9(24.3 \%)$ & $10(27.0 \%)$ & $0(0.0 \%)$ & \\
\hline 3 & $1(11.1 \%)$ & $6(66.7 \%)$ & $2(22.2 \%)$ & $0(0.0 \%)$ & \\
\hline 4 & $1(20.0 \%)$ & $2(40.0 \%)$ & $2(40.0 \%)$ & $0(0.0 \%)$ & \\
\hline 5 & $2(33.3 \%)$ & $2(33.3 \%)$ & $2(33.3 \%)$ & $0(0.0 \%)$ & \\
\hline \multicolumn{6}{|c|}{ Religion } \\
\hline Hindu & $17(40.5 \%)$ & $11(26.2 \%)$ & $14(33.3 \%)$ & $0(0 \%)$ & \multirow{3}{*}{$0.17(6)$} \\
\hline Muslim & $17(32.1 \%)$ & $21(39.6 \%)$ & $12(22.6 \%)$ & $3(5.7 \%)$ & \\
\hline Christian & $8(61.5 \%)$ & $2(15.4 \%)$ & $3(23.1 \%)$ & $0(0 \%)$ & \\
\hline \multicolumn{6}{|c|}{ Background } \\
\hline Rural & $15(31.9 \%)$ & $16(34.0 \%)$ & $16(31.9 \%)$ & $1(2.1 \%)$ & \multirow[b]{2}{*}{$0.54(3)$} \\
\hline Urban & $27(44.3 \%)$ & $18(29.5 \%)$ & $14(23.0 \%)$ & $2(3.3 \%)$ & \\
\hline \multicolumn{6}{|c|}{ Family type } \\
\hline Joint & $13(38.2 \%)$ & $14(41.2 \%)$ & $7(20.6 \%)$ & $0(0.0 \%)$ & \multirow{2}{*}{$0.31(3)$} \\
\hline Nuclear & $29(39.2 \%)$ & $20(27.0 \%)$ & $22(29.7 \%)$ & $3(4.1 \%)$ & \\
\hline \multicolumn{6}{|c|}{ Marriage-Consanguineous(CM)/Non consanguineous(NCM) } \\
\hline $\mathrm{CM}$ & $16(41.0 \%)$ & $13(33.3 \%)$ & $10(25.6 \%)$ & $0(0.0 \%)$ & \multirow{2}{*}{$0.60(3)$} \\
\hline NCM & $26(37.7 \%)$ & $21(30.4 \%)$ & $19(27.5 \%)$ & $3(4.3 \%)$ & \\
\hline \multicolumn{6}{|c|}{ Family history of Mental Retardation } \\
\hline None & $33(37.1 \%)$ & $29(32.6 \%)$ & $25(28.1 \%)$ & $2(2.2 \%)$ & \multirow{3}{*}{$0.82(6)$} \\
\hline One Sib & $5(45.5 \%)$ & $3(27.3 \%)$ & $2(18.2 \%)$ & $1(9.1 \%)$ & \\
\hline Two Sibs & $4(50 \%)$ & $2(25 \%)$ & $2(25 \%)$ & $0(0 \%)$ & \\
\hline
\end{tabular}

* Statistically Significant 


\begin{tabular}{|c|c|c|c|c|c|}
\hline Parameter & Mild & Moderate & Severe & Profound & Chi-sq;df \\
\hline \multicolumn{6}{|c|}{ Mothers age at conception } \\
\hline $15-20$ & $26(39.4 \%)$ & $22(33.3 \%)$ & $16(24.2 \%)$ & $2(3 \%)$ & \multirow{3}{*}{$0.973(6)$} \\
\hline $21-30$ & $14(37.8 \%)$ & $10(27 \%)$ & $12(32.4 \%)$ & $1(2.7 \%)$ & \\
\hline $31-40$ & $2(40 \%)$ & $2(40 \%)$ & $1(20 \%)$ & $0(0 \%)$ & \\
\hline \multicolumn{6}{|c|}{ Fathers age at conception } \\
\hline $15-20$ & $7(50.0 \%)$ & $5(35.7 \%)$ & $2(14.3 \%)$ & $0(0 \%)$ & \multirow{4}{*}{$0.7(9)$} \\
\hline $21-30$ & $27(40.9 \%)$ & $21(31.8 \%)$ & $16(24.2 \%)$ & $2(3.0 \%)$ & \\
\hline $31-40$ & $7(28.0 \%)$ & $8(32.0 \%)$ & $9(36.0 \%)$ & $1(4.0 \%)$ & \\
\hline$\geq 41$ & $1(33.3 \%)$ & $0(0.0 \%)$ & $2(66.7 \%)$ & $0(0.0 \%)$ & \\
\hline \multicolumn{6}{|c|}{ Fathers literacy } \\
\hline Illiterate & $22(37.9 \%)$ & $18(31.0 \%)$ & $17(29.3 \%)$ & $1(1.7 \%)$ & \multirow{2}{*}{$0.84(3)$} \\
\hline Literate & $20(40.0 \%)$ & $16(32.0 \%)$ & $12(24.0 \%)$ & $2(4.0 \%)$ & \\
\hline \multicolumn{6}{|c|}{ Mothers literacy } \\
\hline Illiterate & $25(33.3 \%)$ & $24(32.0 \%)$ & $23(30.7 \%)$ & $3(4.0 \%)$ & \multirow[b]{2}{*}{$0.2(3)$} \\
\hline Literate & $17(51.5 \%)$ & $10(30.3 \%)$ & $6(18.2 \%)$ & $0(0.0 \%)$ & \\
\hline \multicolumn{6}{|c|}{ Mothers Occupation } \\
\hline Housewife & $11(44.0 \%)$ & $5(20.0 \%)$ & $7(28.0 \%)$ & $2(8.0 \%)$ & \multirow{4}{*}{$0.36(9)$} \\
\hline Unskilled & $21(33.3 \%)$ & $22(34.9 \%)$ & $19(30.2 \%)$ & $1(1.6 \%)$ & \\
\hline Skilled & $10(55.6 \%)$ & $6(33.3 \%)$ & $2(11.1 \%)$ & $0(0.0 \%)$ & \\
\hline Professional & $0(0.0 \%)$ & $1(50.0 \%)$ & $1(50.0 \%)$ & $0(0.0 \%)$ & \\
\hline \multicolumn{6}{|c|}{ Fathers occupation } \\
\hline Unskilled & $22(37.9 \%)$ & $18(31.0 \%)$ & $17(29.3 \%)$ & $1(1.7 \%)$ & \multirow{3}{*}{$0.4(6)$} \\
\hline Skilled & $18(40.0 \%)$ & $15(33.3 \%)$ & $11(24.4 \%)$ & $1(2.2 \%)$ & \\
\hline Professional & $2(40.0 \%)$ & $1(20.0 \%)$ & $1(20.0 \%)$ & $1(20.0 \%)$ & \\
\hline \multicolumn{6}{|c|}{ Monthly Income range } \\
\hline Rs.1600-8000 & $19(35.2 \%)$ & $16(29.6 \%)$ & $18(33.3 \%)$ & $1(1.9 \%)$ & \multirow{3}{*}{$0.06(6)$} \\
\hline Rs.8010-16000 & $6(23.1 \%)$ & $13(50.0 \%)$ & $6(23.1 \%)$ & $1(3.8 \%)$ & \\
\hline$\geq$ Rs16010 & $17(60.7 \%)$ & $5(17.9 \%)$ & $5(17.9 \%)$ & $1(3.6 \%)$ & \\
\hline \multicolumn{6}{|c|}{ Socioeconomic Status } \\
\hline Upper & $17(60.7 \%)$ & $5(17.9 \%)$ & $5(17.9 \%)$ & $1(3.6 \%)$ & \multirow{2}{*}{$0.04(3)^{*}$} \\
\hline Lower & $25(31.3 \%)$ & $29(36.3 \%)$ & $24(30 \%)$ & $2(2.5 \%)$ & \\
\hline
\end{tabular}

* Statistically Significant

\begin{tabular}{|c|c|c|c|c|c|}
\hline Parameter & Mild & Moderate & Severe & Profound & Chi-sq;df \\
\hline \multicolumn{6}{|c|}{ Antenatal History } \\
\hline Anaemia & $4(33.3 \%)$ & $7(58.3 \%)$ & $1(8.3 \%)$ & $0(0 \%)$ & \multirow{3}{*}{$0.4(6)$} \\
\hline $\begin{array}{l}\text { Pregnancy } \\
\text { induced } \\
\text { Hypertension }\end{array}$ & $8(44.4 \%)$ & $5(27.8 \%)$ & $5(27.8 \%)$ & $0(0 \%)$ & \\
\hline Uncomplicated & $30(38.5 \%)$ & $22(28.2 \%)$ & $23(29.5 \%)$ & $3(3.8 \%)$ & \\
\hline \multicolumn{6}{|c|}{ Term of pregnancy } \\
\hline Full term & $35(38.5 \%)$ & $28(30.8 \%)$ & $25(27.5 \%)$ & $3(3.3 \%)$ & \multirow{2}{*}{$0.86(3)$} \\
\hline Preterm & $7(41.2 \%)$ & $6(35.3 \%)$ & $4(23.5 \%)$ & $0(0 \%)$ & \\
\hline \multicolumn{6}{|c|}{ Delivery } \\
\hline $\begin{array}{l}\text { Normal } \\
\text { delivery }\end{array}$ & $29(36.7 \%)$ & $26(32.9 \%)$ & $22(27.8 \%)$ & $2(2.5 \%)$ & \multirow{2}{*}{$0.87(3)$} \\
\hline Caesarean & $13(44.8 \%)$ & $8(27.6 \%)$ & $7(24.1 \%)$ & $1(3.4 \%)$ & \\
\hline \multicolumn{6}{|c|}{ Birth Asphyxia } \\
\hline Present & $14(35.9 \%)$ & $13(33.3 \%)$ & $12(30.8 \%)$ & $0(0 \%)$ & \multirow{2}{*}{$0.52(3)$} \\
\hline Absent & $28(40.6 \%)$ & $21(30.4 \%)$ & $17(24.6 \%)$ & $3(4.3 \%)$ & \\
\hline \multicolumn{6}{|c|}{ Hypoxic Ischemic Encephalopathy } \\
\hline Absent & $32(41.6 \%)$ & $23(29.9 \%)$ & $19(24.7 \%)$ & $3(3.9 \%)$ & \multirow{4}{*}{$0.79(9)$} \\
\hline Grade 1 & $7(38.9 \%)$ & $6(33.3 \%)$ & $5(27.8 \%)$ & $0(0.0 \%)$ & \\
\hline Grade 2 & $3(25.0 \%)$ & $5(41.7 \%)$ & $4(33.3 \%)$ & $0(0 \%)$ & \\
\hline Grade 3 & $0(0 \%)$ & $0(0 \%)$ & $1(100 \%)$ & $0(0 \%)$ & \\
\hline \multicolumn{6}{|c|}{ Neonatal Seizures } \\
\hline Absent & $38(40.9 \%)$ & $29(31.2 \%)$ & $23(24.7 \%)$ & $3(3.2 \%)$ & \multirow{2}{*}{$0.51(3)$} \\
\hline Present & $4(26.7 \%)$ & $5(33.3 \%)$ & $6(40 \%)$ & $0(0 \%)$ & \\
\hline
\end{tabular}




\begin{tabular}{|c|c|c|c|c|c|}
\hline \multicolumn{7}{|c|}{ Neonatal Jaundice } \\
\cline { 1 - 4 } Absent & $40(38.5 \%)$ & $33(31.7 \%)$ & $28(26.9 \%)$ & $3(2.9 \%)$ & \multirow{2}{*}{$0.96(3)$} \\
\hline Present & $2(50 \%)$ & $1(25 \%)$ & $1(25 \%)$ & $0(0 \%)$ & \\
\hline \multicolumn{7}{|c|}{ Septicaemia } \\
\hline Absent & $41(39.0 \%)$ & $34(32.4 \%)$ & $28(26.7 \%)$ & $2(1.9 \%)$ & \multirow{2}{*}{$0.01(3)^{*}$} \\
\hline Present & $1(33.3 \%)$ & $0(0.0 \%)$ & $1(33.3 \%)$ & $1(33.3 \%)$ & \\
\hline \multicolumn{7}{|c|}{ Meningitis/Encephalitis } \\
\hline Absent & $40(39.6 \%)$ & $34(33.7 \%)$ & $24(23.8 \%)$ & $3(3 \%)$ & \multirow{2}{*}{$0.04(3)^{*}$} \\
\hline Present & $2(28.6 \%)$ & $0(0 \%)$ & $5(71.4 \%)$ & $0(0 \%)$ & \\
\hline \multicolumn{7}{|c|}{ Table 3: Perinatal factors and severity of mental retardation }
\end{tabular}

* Statistically Significant

\begin{tabular}{|c|c|c|c|c|c|}
\hline Parameter & Mild & Moderate & Severe & Profound & Chi-sq(df) \\
\hline \multicolumn{6}{|c|}{ Seizures } \\
\hline Absent & $36(42.9 \%)$ & $28(33.3 \%)$ & $20(23.8 \%)$ & $0(0 \%)$ & \multirow{2}{*}{$0.003(3)^{*}$} \\
\hline Present & $6(25 \%)$ & $6(25 \%)$ & $9(37.5 \%)$ & $3(12.5 \%)$ & \\
\hline \multicolumn{6}{|c|}{ Downs } \\
\hline Absent & $40(38.8 \%)$ & $33(32 \%)$ & $27(26.2 \%)$ & $3(2.9 \%)$ & \multirow{2}{*}{$0.872(3)$} \\
\hline Present & $2(40 \%)$ & $1(20 \%)$ & $2(40 \%)$ & $0(0 \%)$ & \\
\hline \multicolumn{6}{|c|}{ Cerebral palsy } \\
\hline Absent & $41(41.4 \%)$ & $33(33.3 \%)$ & $24(24.2 \%)$ & $1(1 \%)$ & \multirow{2}{*}{$0.000(3)^{*}$} \\
\hline Present & $1(11.1 \%)$ & $1(11.1 \%)$ & $5(55.6 \%)$ & $2(22.2 \%)$ & \\
\hline \multicolumn{6}{|c|}{ Hypothyroidism } \\
\hline Absent & $42(39.6 \%)$ & $33(31.1 \%)$ & $28(26.4 \%)$ & $3(2.8 \%)$ & \multirow{2}{*}{$0.687(3)$} \\
\hline Present & $0(0 \%)$ & $1(50 \%)$ & $1(50 \%)$ & $0(0 \%)$ & \\
\hline \multicolumn{6}{|c|}{ Squint } \\
\hline Absent & $37(37.8 \%)$ & $29(29.6 \%)$ & $29(29.6 \%)$ & $3(3.1 \%)$ & \multirow{2}{*}{$0.19(3)$} \\
\hline Present & $5(50 \%)$ & $5(50 \%)$ & $0(0 \%)$ & $0(0 \%)$ & \\
\hline \multicolumn{6}{|c|}{ Hearing Impaired } \\
\hline Absent & $40(39.6 \%)$ & $32(31.7 \%)$ & $26(25.7 \%)$ & $3(3 \%)$ & \multirow{2}{*}{$0.77(3)$} \\
\hline Present & $2(28.6 \%)$ & $2(28.6 \%)$ & $3(42.9 \%)$ & $0(0 \%)$ & \\
\hline \multicolumn{6}{|c|}{ Vision Impaired } \\
\hline Absent & $41(38.7 \%)$ & $34(32.1 \%)$ & $28(26.4 \%)$ & $3(2.8 \%)$ & \multirow{2}{*}{$0.76(3)$} \\
\hline Present & $1(50 \%)$ & $0(0 \%)$ & $1(50 \%)$ & $0(0 \%)$ & \\
\hline \multicolumn{6}{|c|}{ Microcephaly } \\
\hline Absent & $40(40 \%)$ & $32(32 \%)$ & $26(26 \%)$ & $2(2 \%)$ & \multirow{2}{*}{$0.28(3)$} \\
\hline Present & $2(25 \%)$ & $2(25 \%)$ & $3(37.5 \%)$ & $1(12.5 \%)$ & \\
\hline \multicolumn{6}{|c|}{ Congenital Heart Disease } \\
\hline Absent & $41(38.3 \%)$ & $34(31.8 \%)$ & $29(27.1 \%)$ & $3(2.8 \%)$ & \multirow{2}{*}{$0.68(3)$} \\
\hline Present & $1(100.0 \%)$ & $0(0.0 \%)$ & $0(0.0 \%)$ & $0(0.0 \%)$ & \\
\hline \multicolumn{6}{|c|}{ Cerebro Vascular Accident } \\
\hline Absent & $41(38.7 \%)$ & $33(31.1 \%)$ & $29(27.4 \%)$ & $3(2.8 \%)$ & \multirow{2}{*}{$0.83(3)$} \\
\hline present & $1(50.0 \%)$ & $1(50.0 \%)$ & $0(0.0 \%)$ & $0(0.0 \%)$ & \\
\hline \multicolumn{6}{|c|}{ Behavioural problems } \\
\hline Absent & $13(30.2 \%)$ & $14(32.6 \%)$ & $13(30.2 \%)$ & $3(7.0 \%)$ & \multirow{2}{*}{$0.10(3)$} \\
\hline Present & $29(44.6 \%)$ & $20(30.8 \%)$ & $16(24.6 \%)$ & $0(0.0 \%)$ & \\
\hline \multicolumn{6}{|c|}{ Autism } \\
\hline Absent & $41(39.4 \%)$ & $33(31.7 \%)$ & $27(26.0 \%)$ & $3(2.9 \%)$ & \multirow{2}{*}{$0.75(3)$} \\
\hline Present & $1(25.0 \%)$ & $1(25.0 \%)$ & $2(50.0 \%)$ & $0(0.0 \%)$ & \\
\hline & Table & Co morbidi & s and sev & of $M R$ & \\
\hline
\end{tabular}

\footnotetext{
* Statistically Significant
} 